CORPUS PUBLISHERS

\section{Journal of Mineral} and Material

\section{Science (JMMS)}

\section{Volume 2 Issue 2, 2021}

\section{Article Information}

Received date : March 20, 2021

Published date: April 05, 2021

\section{*Corresponding author}

N I Buravchuk, FGAOU VO, Southern Federal University, Rostov-on-Don, Russia

\section{Keywords}

Steel-making slag; Slag processing;

Fractionated aggregate; Crushing screenings; Slag-mineral mixtures; Road pavements

Distributed under Creative Commons CC-BY 4.0

\title{
Study of Steel Melted Slags as Materials for Road Construction
}

\author{
Buravchuk NI* and Guryanova OV \\ FGAOU VO, Southern Federal University, Rostov-on-Don, Russia
}

\section{Abstract}

The properties of steel-making slag concentrated in dumps in the Rostov region have been investigated. The possibility of using them as materials for road construction is shown. Fractionated aggregates from steelmaking slag can be used for the construction of subgrade, foundations and layers of pavement. They are applicable in asphalt mixes for pavements. Materials from the investigated steelmaking slag can be used in the construction and repair of roads of III - IV categories of roads.

\section{Introduction}

The economic component of the concept of sustainable development implies the optimal use of natural resources and the use of efficient technologies, the creation of environmentally friendly products, minimization, processing and disposal of waste [1]. In this context, the utilization of technogenic raw materials becomes comprehensive and becomes part of the modern economic worldview. Of the generated and accumulated waste, by-products of the metallurgical industry are large-tonnage. In terms of reserves and usefulness of properties, metallurgical slags are classified as technogenic deposits. Road construction is the most material-intensive sector of the use of mineral natural resources. Metallurgical steel-making slags can become a significan reserve for providing this industry with high-quality and inexpensive secondary raw materials that are not inferior in properties to natural raw materials. Both researchers and industrial workers are interested in the use of steel-making slags. The relevance of this topic is growing, firstly, in connection with their numerous reserves, on the other hand, with the growing depletion of natural raw materials and the complication of its extraction at great depths. In this regard, research on expanding the range of use of steel slags in road construction, both as non-metallic materials and in the composition of mineral mixtures, deserves increased attention.

\section{Research Methods}

For the use of steel slag in road construction, technological samples were taken from the dumps. Analytical and laboratory studies have been carried out. A comprehensive assessment of the quality of technogenic raw materials has been carried out. Thi approach consists in obtaining primary information on the chemical and material composition of raw materials. Subsequently, physical, mechanical and technological tests were carried out, according to which a complete assessment of the quality of raw materials was given in accordance with the requirements of regulatory and technical documentation. Technological modes are being worked out, which are then checked and corrected in pilot-industrial conditions during the construction of pilot road sections. Monitoring of the state of the experimental sites was carried out. Based on the results of research and production tests, the final adjustment of the recommendations for the use of steel-making slags was carried out.

Results and Discussion

Metallurgical slags are technogenic materials. Interest in the processing and use of steel-making slag is caused by the need to reduce the environmental load on the environment and expand the mineral resource base of road construction [2-6] The purpose of this work is to study the properties of steel-making slags and establish the possibility of using them in road construction. The object of research is slags located on the territory of the Rostov region. Steel-making slags are formed when steel is smelted from pig iron. In slags, the most important acidic oxide is $\mathrm{SiO}_{2}$ Metallurgical slags are usually alloying of basic oxides with $\mathrm{SiO}_{2}$, which are predominantly silicate formations. In terms of chemical composition, the investigated steel-making slags belong to the main ones: the $\mathrm{CaO} / \mathrm{SiO}_{2}$ ratio is 1.33-2.22. The chemical composition of the slags is given in Table 1 .

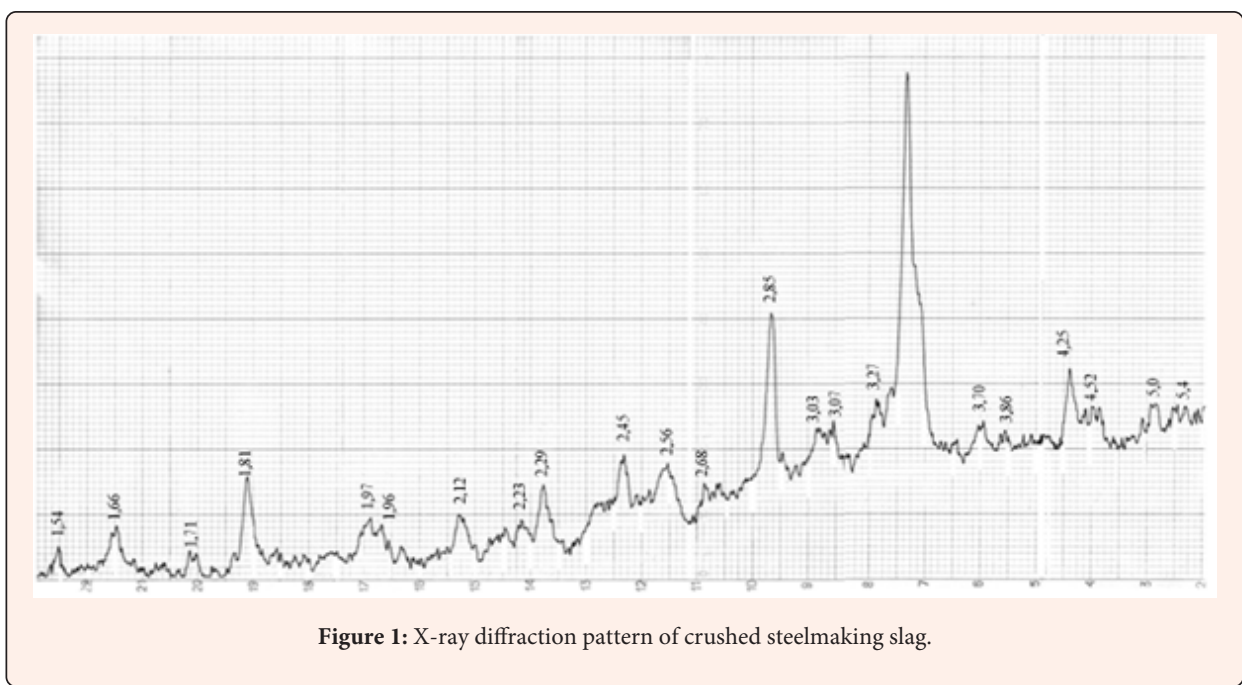


Table 1: The chemical composition of the slags.

\begin{tabular}{|c|c|c|c|c|c|c|c|c|}
\hline \multirow[b]{2}{*}{ Steel-Making Slag } & \multicolumn{8}{|c|}{ Chemical Composition, Weight.\% } \\
\hline & $\mathrm{CaO}$ & $\mathrm{SiO}_{2}$ & $\mathrm{Al}_{2} \mathrm{O}_{3}$ & $\mathrm{MgO}$ & $\mathrm{MnO}$ & $\mathrm{Fe}$ & $\mathrm{Fe}_{2} \mathrm{O}_{3}$ & S \\
\hline Reducing & $32,0-51,0$ & $21,0-23,0$ & $4,0-5,0$ & $1,5-2,5$ & $3,5-6,0$ & $12,0-21,0$ & $1,0-5,5$ & $1,2-2,5$ \\
\hline Oxidizing & $8,0-11,0$ & $38,0-51,0$ & $2,0-7,0$ & $6,0-9,0$ & $3,0-13,0$ & $5,0-25,0$ & $1,0-6,0$ & $0,3-0,8$ \\
\hline
\end{tabular}

(Figures 1 \& 2) show X-ray diffraction patterns of samples of crushed steelmaking slag and screenings of crushing slag. In terms of mineralogical composition, the samples of crushed slag and slag screening differ little from each other. Both samples contain quartz and its modifications, ferruginous compounds such as limonite and hydrogoethite, hematite, magnetite, mullite, feldspars, clay minerals such as kaolinite and hydromica, alumina, and calcite. Calcium silicates in slags are present in the form of various modifications of belite, melilite, pseudo-wollastanite, oxides and hydroxides of magnesium, calcium in a free state, and a low-temperature modification of quartz.

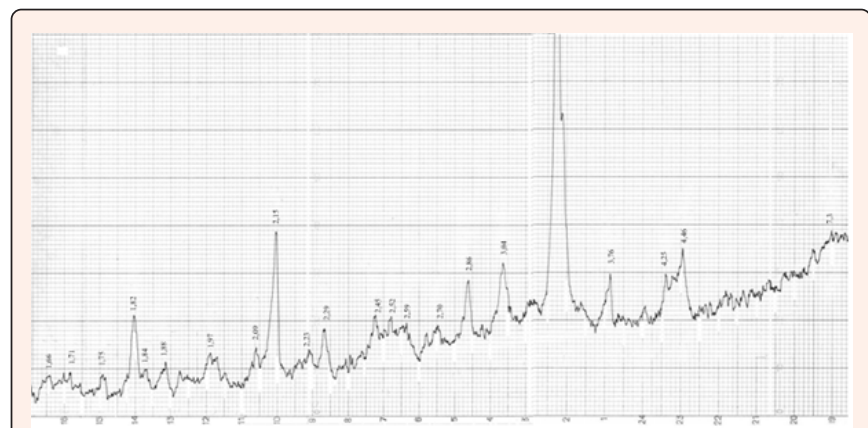

Figure 2: X-ray diffraction pattern of steelmaking slag crushing screenings.

Thermograms of crushed slag and crushing screenings are shown in Figure 3. The composition of the ground slag screening is dominated by the glass phase, which is confirmed by the DTA curve: it rises sharply, starting from a temperature of $120^{\circ} \mathrm{C}$. This sample shows a higher content of the clay mineral-kaolinite. The thermal effect at a temperature of $560{ }^{\circ} \mathrm{C}$ is deeper than in a sample of crushed slag. This sample contains a small amount of clay mineral-montmorillonite. Carbonates were found in both samples, but there are more of them in the sample of ground screening: the thermal effect at a temperature of $860^{\circ} \mathrm{C}$ is deeper. In a sample of crushed slag, this effect is shifted to the region of lower temperatures $\left(830^{\circ} \mathrm{C}\right)$. Both samples contain carbonized carbonaceous particles that burn out at a temperature of $800^{\circ} \mathrm{C}$. The weight loss in the ground screening sample is greater than in the crushed slag. This is due to the increased content of clay minerals, unburned coal particles and calcium carbonates in the ground screening of slag. Sulfur is present mainly in the form of iron and calcium sulfides. Carbon is present in the form of a small amount of impurities in the free state and partly in the form of iron and calcium carbides.

The structure and density of slags depends on the chemical and mineralogical composition and the rate of cooling of the melt. Upon slow cooling, a dense crystalline structure of the slag is formed. At fast - porous glassy structure. The most promising and less costly direction of using steelmaking slag is the production of fractionated aggregates. A necessary condition for obtaining high-quality aggregates from slags is their resistance to various types of decomposition. Slags are subject to silicate and lime decomposition. These transformations are accompanied by regular imputation of volume, which leads to the decomposition of the slag. Lime in the slag is usually in varying degrees of burnout, so the decomposition process in natural conditions takes a long time. To obtain a stable structure, the hardened slag must be kept in dumps for at least a year. Slags can be used after preliminary aging for 1-2 years to complete self-decomposition processes with subsequent separation of decomposition products and into fine-grained and coarsegrained parts. The processing of steel-making slags is fraught with significant difficulties due to the high abrasiveness of the slags and the increased metal content. In terms of strength, steel-making slags are not inferior to granites and quartzites and are many times superior to limestones. Crushed slag from metallurgical slag can be obtained by crushing The processing of slag into aggregates can be carried out in crushing and screening plants with the receipt of fractionated aggregates and maximum metal recovery. As a result of slag processing at crushing and screening plants by screening and dry magnetic separation, it is possible to obtain crushed stone of the following fractions: from 5 to $10 \mathrm{~mm}$; st. 10 to $20 \mathrm{~mm}$; st. 20 to $40 \mathrm{~mm}$; st. 40 to $70 \mathrm{~mm}$; st. 70 to $120 \mathrm{~mm}$, as well as a mixture of fractions. The presence of metal inclusions in crushed stone is allowed no more than $5 \%$ by weight. The grain composition of crushed slag, like other aggregates, is selected according to the principle of ensuring minimum voidness. Screenings of crushing slag with a grain size of $0-10 \mathrm{~mm}$ can be used as a fine-grained aggregate. A sand fraction $(0-5 \mathrm{~mm})$ can be separated from the crushing screenings. From the crushing screenings, a finely ground fraction is obtained, which is used as an active additive. (Table 2) shows the physical and mechanical properties of crushed stone from the investigated steel-making slag.

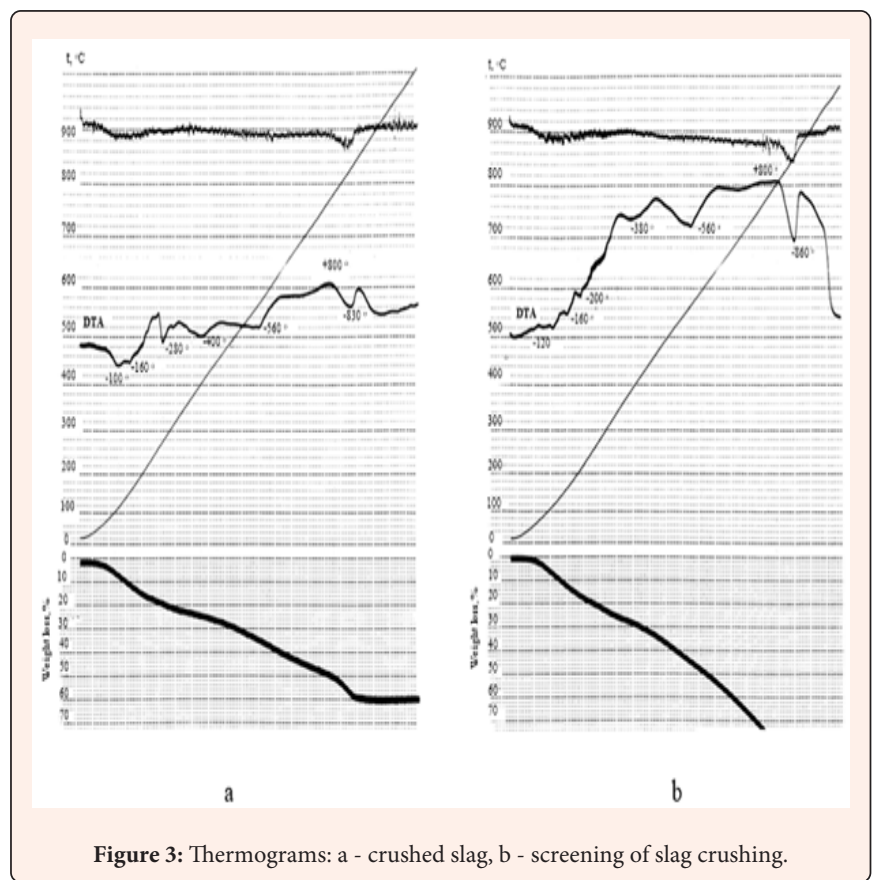

The obtained fillers from steel-making slags are characterized by a fairly stable structure. One of the features of steelmaking slag aggregates is the absence of contaminants, clumps of clay. According to its technical characteristics, crushed stone and screenings from steelmaking slags meet the requirements of regulatory documents for slag aggregates for road construction. The use of man-made raw materials in road construction will allow replacing expensive materials (for example, imported non-metallic materials, granite crushed stone, etc.) with cheaper ones, reducing the consumption of stone materials and reducing the negative impact on the natural environment. The main characteristics that determine the possibility of using slags in road construction are: grain size composition, strength, frost resistance, structure stability. For the device of the lower layers of the bases of the pavements, the compositions of slag-mineral mixtures were selected. The components of the compositions were clay soils, crushed slags and screenings of crushing slags, and cement additives (from 1 to $2 \%$ ) were used as an activator. In (Figure 4) shows strength indicators, and (Figure 5)the values of water absorption of the investigated compositions depending on the total content of slag-containing material (slag+screenings). Samples cylinders $(h=50$ and $d=50$ $\mathrm{mm}$ ) of experimental compositions were tested 28 days after strength gain under natural hardening conditions (humidity - 90-95\%, temperature - $18-20^{\circ} \mathrm{C}$ ). An increase in the content of cement in the composition of mixtures leads to an increase in strength and a decrease in water absorption. Maximum strength values are noted in the range of 7.17.6 MPa. Slag-mineral mixtures, laid in the base layer, practically do not require special maintenance. They mix well and are easily compacted, allow the laying of asphalt concrete pavements immediately after the compaction of the base. Asphalt concrete pavement, laid on a slag-mineral base, combines well with it. 
Table 2: Shows the physical and mechanical properties of crushed stone from the investigated steel-making slag.

\begin{tabular}{|c|c|c|c|c|c|}
\hline \multirow[b]{2}{*}{ Main Factors Crushed Stone Quality } & \multicolumn{5}{|c|}{ Fraction Size, mm } \\
\hline & of 5 to 10 & st. 10 to 20 & st. 20 to 40 & st. 40 to 70 & st. 70 to 120 \\
\hline Crush strength grade & 1200 & 1200 & 1000 & 600 & 600 \\
\hline Frost resistance grade & F300 & F300 & F200 & F100 & F100 \\
\hline Water resistance grade & B1 & B1 & B1 & B1 & B1 \\
\hline Content of dust and clay particles, $\%$ & 2,8 & 2,4 & 1,9 & 1,8 & 1,3 \\
\hline Clay content in lumps, $\%$ & 0,23 & 0,21 & 0,17 & 0,13 & 0,09 \\
\hline Content of lamellar and acicular grains, $\%$ & 1,2 & 1,1 & 0,8 & 0,7 & 0,4 \\
\hline Content of weak rocks, $\%$ & 1,1 & 1,7 & 2,6 & 2,9 & 3,7 \\
\hline Resistance to all types of decomposition, weight loss during decay, $\%$ & 1,50 & 1,25 & 5,15 & 5,25 & 5,70 \\
\hline
\end{tabular}

Table 3: The characteristics of asphalt concrete samples containing slags.

\begin{tabular}{|c|c|c|c|c|c|c|c|}
\hline \multirow[b]{5}{*}{ View and Type Asphalt Concrete } & \multicolumn{7}{|c|}{ Properties of Slag Asphalt Concrete Samples } \\
\hline & \multirow[b]{4}{*}{ Average Density, $\mathrm{kg} / \mathrm{m}^{3}$} & \multirow{3}{*}{\multicolumn{3}{|c|}{$\begin{array}{l}\text { Compressive Strength, MPa } \\
\text { By Coeff. Internal Friction }\end{array}$}} & \multirow{4}{*}{$\begin{array}{l}\text { Coeff. Water Resistance } \\
\text { with Long-Term Water } \\
\text { Saturation }\end{array}$} & \multicolumn{2}{|l|}{ Shear Resistance } \\
\hline & & & & & & \multirow[t]{3}{*}{ By Coeff. Internal Friction } & \multirow[t]{3}{*}{ Shear Grip } \\
\hline & & & & & & & \\
\hline & & $0^{\circ} \mathrm{C}$ & $20^{\circ} \mathrm{C}$ & $50^{\circ} \mathrm{C}$ & & & \\
\hline Dense A & 2470 & 6,6 & 3,5 & 5,8 & 0,92 & 0,88 & 0,33 \\
\hline \multirow[b]{2}{*}{ Dense B } & 2490 & 7,4 & 3,8 & 6,9 & 0,94 & 0,89 & 0,40 \\
\hline & 2490 & 7,1 & 4,0 & 6,6 & 0,96 & 0,90 & 0,42 \\
\hline \multirow[b]{2}{*}{ G } & 2510 & 5,6 & 2,7 & 4,8 & 0,88 & - & - \\
\hline & 2520 & 5,4 & 2,5 & 4,4 & 0,90 & - & - \\
\hline Fine-Grained & 2470 & 8,8 & 4,1 & 5,0 & 0,93 & - & - \\
\hline
\end{tabular}

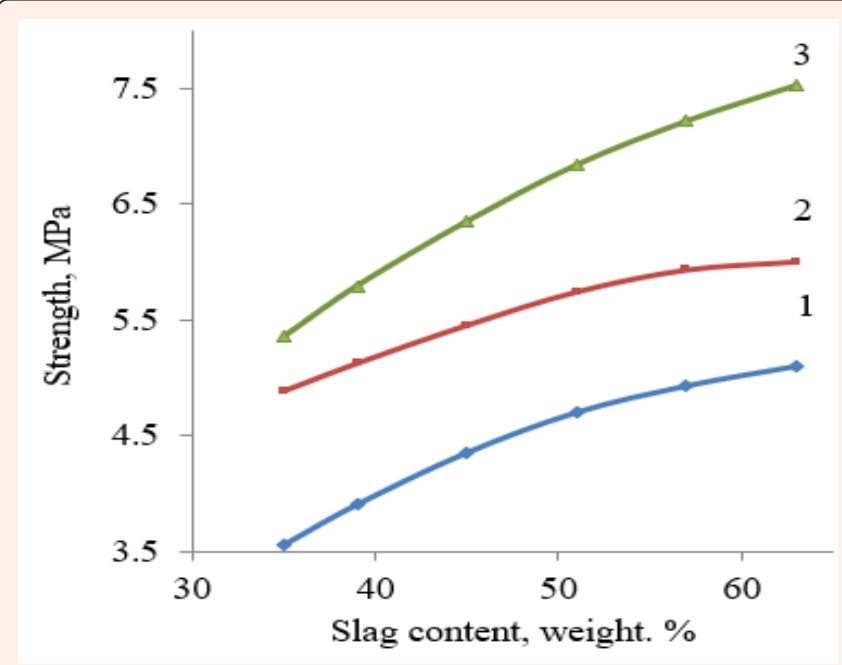

Figure 4: Strength of slag-soil mixtures with cement additives, $\%$ : 1-1.0; 2-2.0; 3-3.0.

To ensure the stable operation of the foundation, a strict selection of the granulometric composition of the skeletal part, consisting of a sand-crushed stone mixture, is required. For the device of the roadbed, it is possible to recommend the use of a fraction sv. 40 to $80 \mathrm{~mm}$ and from 0 to $10 \mathrm{~mm}$, a fine aggregate is a fraction from 0 to $10 \mathrm{~mm}$. The grade of crushed stone should be 1000,1200 in terms of strength, and F150 in terms of frost resistance. The composition of the crushed stone slag mixture in combination with the screening of the crushing of the slag contributes to an increase in the efficiency of compaction of the layer materials to the required density values (the compaction coefficient is 0.98 ). The technology of construction of the subgrade and the base includes layer-by-layer build-up of the embankment from layers of different grain size and compaction with rollers of each layer to the density specified according to the project. The presence of slag activity contributes to the formation in the road structure of a strong composition having an average compressive strength of at least 5.0-5.5 $\mathrm{MPa}$. When arranging crushed stone bases and coatings according to the wedge method, crushed slag of the fraction of St. 40 to $70(80) \mathrm{mm}$, and crushed stone crushed stone of St. 5 to $20 \mathrm{~mm}$ or crushed stone-sand slag mixture of fraction from 0 to $10 \mathrm{~mm}$. The arrangement of foundations and coatings by the method of jamming with the use of crushed slag is carried out similarly to the arrangement of foundations and coatings from natural stone materials: the distribution of crushed stone-sand mixture and compaction. The most economical designs are with the use of steel-making slag with a particle size of up to $40 \mathrm{~mm}$. During operation, the modulus of elasticity of the layers in the base slowly increases due to the increase in strength.

Steel slag aggregates can also be used to prepare organomineral mixtures. Good adhesion of bitumen with materials from steelmaking slag was experimentally established. The adhesion of the binder to the surface of the slag particles and the screening of slag crushing is high. The strength in the contact zone is a serious obstacle to the formation of microcracks. The characteristics of asphalt concrete samples containing slags are shown in Table 3. Asphalt concrete based on slags in its structural and mechanical properties significantly differs from concretes based on natural mineral materials. The essential difference is that slags interact with organic binders and with water. The structural features and properties of the slags contribute to good adhesion and interaction with bitumen. Asphalt concrete pavements with slag aggregate are characterized by high strength, abrasion resistance, high coefficient of adhesion, and the absence of shear deformations. Also, these coatings are distinguished by increased resistance to shock loads at positive and negative temperatures, higher heat resistance than asphalt concrete based on natural 
mineral aggregates. With prolonged contact with water on the surface of the slag grains, hydration products and insoluble organ mineral compounds are formed, the pores of the slag material germinate with crystalline hydrate neoplasms, which subsequently prevents water access to them and leads to an increase in the frost resistance of asphalt concrete. The investigated compositions of asphalt concrete mixtures containing steel-making slags can be recommended for paving on roadsides of III - IV categories. Variants of pavement designs using steel-making slags are shown in (Figure 6).

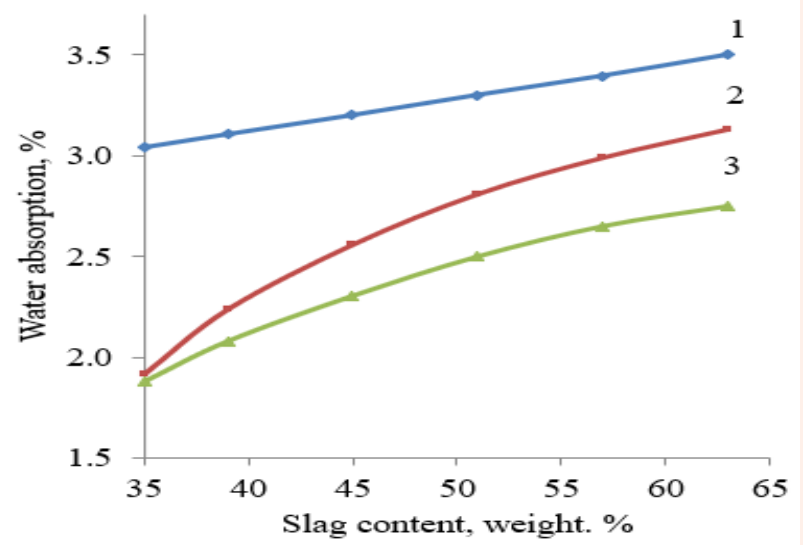

Figure 5: Water absorption of slag soil mixtures with cement additives, $\%: 1-1.0$ $2-2.0 ; 3-3.0$.

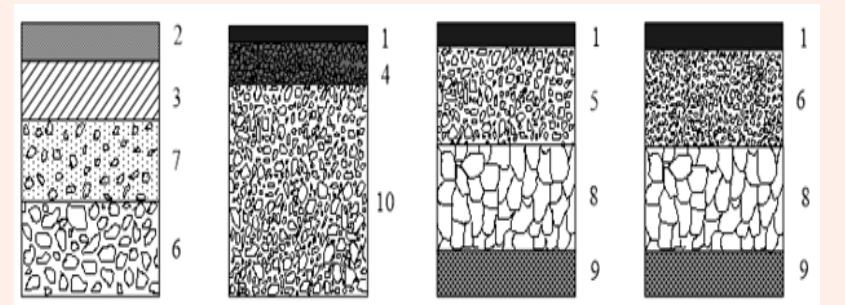

Figure 6: Construction of pavements using steel-making slag
1 - surface treatment
2 - dense asphalt concrete;
3 - porous asphalt concrete
4 - impregnated slag crushed stone
5 - fractionated crushed stone, $25-70 \mathrm{~mm}$ in size;
6 - fractionated crushed stone, $15-40 \mathrm{~mm}$ in size;
7 - fractionated crushed stone, $5-20 \mathrm{~mm}$ in size;
8 - very large, crushed slag;
9 - a layer of low-strength slags;
10 - ordinary slag material

The technology of construction of pavement construction layers using slag aggregates is carried out similarly to the construction technology using natural aggregates. Bases and coatings made of organic-mineral mixtures with the use of slag materials can be arranged on roads II, III, IV, V of road-climatic zones. The mixture is produced by mixing on the road or in various types of mixing plants equipped with batch or continuous forced mixing mixers. The research results were tested on experimental sections of access and technological roads of the metallurgical plant in Krasny Sulin, Rostov region. During the long-term operation of the experimental sections of the roads, subsidence, deformations, and destruction of coatings were not observed.

\section{Conclusion}

As a result of the studies, it was found that road construction can become the most promising and material-intensive direction for using slag aggregates. Slag crushed stone and crushed stone-sand mixtures in road construction can be used for the construction of subgrade, slag bases and coatings, as components of asphalt concrete mixtures, from which asphalt concrete bases and coatings are made. Due to the use of steel-making slag, it is possible to significantly expand the raw material base for the construction of highways for various purposes. The use of such materials is especially relevant for the construction of access, technological, rural and regional roads of local importance, the shortage of which is often more than $80 \%$. With the accumulation of positive experience in the operation of roads using steel-making slags, you can continue to use them in roads of higher categories. At the same time, it is possible not only to improve the quality of the structural layers of road pavements, but also to reduce the costs of reconstructing old roads and building new ones, reducing the consumption of natural stone materials and the costs associated with their extraction and restoration of the disturbed landscape. The use of steel-making metallurgical slags in road construction is one of the strategic ways to solve the environmental problem to improve the state of the natural environment in the area of operation of metallurgical plants and the accumulation of slags. Utilization of steel-making metallurgical slag allows solving some environmental problems: reducing the number of quarrying operations for the extraction of natural raw materials, preserving the natural landscape of the earth's surface, freeing land from dumps, and reducing pollution of water and air basins.

\section{Acknowledgement}

Research was financially supported by Southern Federal University, grant No. VnGr-07/2020-04-IM (Ministry of Science and Higher Education of the Russian).

\section{References}

1. (1992) Rio Declaration on Environment and Development. Russia.

2. Trubetskoy KN, Umanets VN (1992) Complex development of technogenic deposits. Gornyi Zhurnal 1: 12-16.

3. Mikhailusov EA (2004) The use of metallurgical waste in the road construction of the forestry complex. Abstract of the Dissertation Cand Tech Sciences, Voronezh. p.19.

4. Kostenko AK (2008) Assessment of the ecological and economic efficiency of using electric steel-making metallurgical slag in road construction. Bulletin of the Belarusian National Technical University: Scientific and Technical Journal 2: 6572

5. Pugin KG, Yushkov VS (2011) Construction of highways using technogenic materials. Bulletin of PSTU Environmental Protection, Transport, Life Safety, Permian. 1: 35-43.

6. Zhukova IA (2012) Theoretical aspects of man-made waste management as production resources of mining regions. TERRA ECONOMICUS 4: 123-126. 